\title{
Preceptoria em saúde: percepções e conhecimento dos preceptores de uma unidade de ensino \\ e assistência
}

\section{Preceptorship: perceptions and knowledge of preceptors in}

\author{
a teaching and health assistance unit
}

\author{
Apio Ricardo Nazareth Dias ${ }^{1}$ \\ apiodias@gmail.com \\ Alna Carolina Mendes Paranhos ${ }^{2}$ \\ alna.paranhos@gmail.com \\ Renato da Costa Teixeira ${ }^{3}$ \\ teixeirarenato@globo.com \\ Robson José de Souza Domingues ${ }^{4}$ \\ domingues100@yahoo.com.br \\ Katia Simone Kietzer ${ }^{5}$ \\ kkietzer@yahoo.com \\ Jofre Jacob da Silva Freitas ${ }^{6}$ \\ jofrefreitas@superig.com.br
}

\section{Resumo}

O preceptor é um profissional da saúde que oferece treinamento prático em ambientes de serviços de saúde. O objetivo do estudo foi avaliar a percepção e conhecimento dos profissionais de saúde que atuam como preceptores, em uma unidade de ensino-assistência, acerca das funções de preceptoria. A pesquisa foi transversal e qualitativa. Na coleta de dados, utilizou-se a técnica de grupos focais com 15 profissionais, entre fisioterapeutas e terapeutas ocupacionais. A partir da análise do discurso, identificaram-se fatores que dificultam a realização das atividades de preceptoria: ausência de política de capacitação, desarticulação entre ensino e assistência; carência de elementos legais que amparem a atividade de preceptoria.

Palavras-chave: Ensino, Preceptoria, Capacitação em serviço, Educação em saúde, Saúde pública

\section{Abstract}

The preceptor is a health professional who offers practical training in health service environments. The aim of this study is to evaluate the perception and knowledge of health professionals who work as preceptors in a teaching and health assistance unit about preceptorship. This is a transversal research with a qualitative approach. For

\footnotetext{
${ }^{1}$ Mestre em Ensino em Saúde, Universidade do Estado do Pará.

${ }^{2}$ Especialista em Reabilitação Neurológica, Universidade do Estado do Pará.

${ }^{3}$ Doutor em Educação, Universidade do Estado do Pará

${ }^{4}$ Doutor em Ciências Biológicas Anatomia, Universidade do Estado do Pará.

${ }^{5}$ Doutora em Neurociências e Biologia Celular, Universidade do Estado do Pará.

${ }^{6}$ Doutor em Ciências, Universidade do Estado do Pará.
}

Revista Educação Online, n. 19, jun-ago 2015, p.83-99 
data collection, we have used focal group technique carried out with 15 professionals among physical and occupational therapists. The discourse analysis technic was used to identify factors that make difficult the development of preceptorship activities: absence of capacitation politics; disarticulation between teaching and health assistance; few legal elements that support preceptorship activities.

Keywords: Teaching, Preceptorship, Service empowerment, Health education, Public health

\section{Introdução}

O preceptor é o profissional de saúde que oferece treinamento prático em ambientes de serviços de saúde e atua na orientação e supervisão de atividades práticas de alunos de graduação e recém-graduados, denominados de residentes. Nesse sentido, o preceptor possui duplo papel: atua como profissional na assistência em saúde e, ao mesmo tempo, assume o compromisso de ensinar, orientar, supervisionar e servir como modelo para o estudante. Geralmente, as atividades educacionais do preceptor estão voltadas para o desenvolvimento de um perfil ancorado na integralidade do cuidado e na equidade da atenção, em consonância com as diretrizes do Sistema Único de Saúde - SUS (DIAS; FREITAS, 2014).

O termo "preceptor" vem do latim praecipio, que significa "mandar com império aos que lhe são inferiores", sendo utilizado para designar os mestres das ordens militares. A partir do século XVI, passa a nomear quem dá preceitos ou instruções, o educador, mentor, instrutor. Na literatura médica, encontram-se diferentes funções para o preceptor, entre as essenciais estão educar, orientar, dar suporte, ensinar e compartilhar experiências que ajudem a melhorar a competência do graduando ou recém-graduado a se adaptar ao exercício da profissão (BOTTI; REGO, 2008). Preceptoria é a palavra sagrada no meio da saúde para designar a função do preceptor, aparecendo inclusive na legislação, podendo ser entendida então como expressão de um conceito (BOTTI; REGO, 2009).

A política do Ministério da Saúde associado com o Ministério da Educação e Cultura (MEC) favorece a inserção de estudantes no ambiente do trabalho em saúde, proporcionando, assim, maior integração do ensino à realidade social, às políticas sociais e ao SUS, e promovendo o desenvolvimento de habilidades e a contextualização da aprendizagem, a fim de garantir a qualidade na educação (TOASSI; DAVOGLIO; LEMOS, 2012). O termo qualidade aqui deve ser entendido 
como aquilo que melhora a vida das pessoas. Em educação, esse termo está diretamente ligado ao bem-viver das comunidades, a partir da comunidade escolar. A qualidade da educação não pode ser boa, se a qualidade do docente, do aluno, da comunidade for ruim. Não há como separar a qualidade da educação da qualidade como um todo, pois não é possível ter qualidade ao entrar na escola e piorar a qualidade ao sair dela (GADOTTI, 2013).

O processo de integração do ensino-serviço público de saúde é preconizado pelas Diretrizes Curriculares Nacionais, para os cursos de graduação na área da saúde, porém, um dos maiores entraves a ser superado diz respeito à capacitação de recursos humanos para atuar na complexidade do SUS. Assim, faz-se necessário um esforço de superação da visão tradicional da saúde, incluindo, na formação do profissional, paradigmas que considerem a saúde como resultante das condições de vida da sociedade, famílias e indivíduos, ou seja, como produto social. Portanto, essa formação precisa ir além das práticas atuais e avançar no delineamento dos possíveis cenários sociais nos quais os cidadãos estão inseridos, identificando as diferentes necessidades de saúde da população e ampliando o foco da formação profissional (GIL et al., 2008).

A preceptoria em saúde tem fundamental importância dentro desse cenário, pois atua justamente na saúde pública. Ao inserir o estudante no ambiente de assistência à saúde, criam-se as condições para que ele saia das instituições de ensino com uma formação que lhe dê a visão da rotina de trabalho do profissional de saúde, preparando esse estudante para se tornar membro da equipe multidisciplinar, com visão ampliada da relação ensino-serviço.

O preceptor em saúde é considerado o profissional que atua dentro do ambiente de assistência à saúde, convertendo-o também em ambiente de ensino para a prática profissional. Sua ação se dá por meio de encontros formais que objetivam o progresso na prática clínica do aluno de graduação ou de residência, construindo, orientando e facilitando a aquisição de conhecimentos relativos a cada área de atuação e da prática diária do serviço de saúde. A função primordial do preceptor é intermediar a formação e o desenvolvimento de habilidades clínicas e avaliar o profissional em formação (BOTTI; REGO, 2008; ROCHA; RIBEIRO, 2012). Para o MEC, o preceptor pode estar vinculado à instituição formadora ou executora, 
com formação mínima de especialista. Sua função se caracteriza por realizar a supervisão direta de atividades práticas dos estudantes (BRASIL, 2014).

Historicamente não há exigência de formação docente para o exercício da preceptoria, não havendo definição de requisitos mínimos necessários nem avaliação desses atributos. O preceptor é muito exigido, mas, em geral, não existe nenhum programa para capacitação, qualificação, formação pedagógica e didática, nem remuneração diferenciada para esses profissionais, uma vez que se acredita que, para ser preceptor, basta ser um bom profissional de saúde (SANTOS, 2012).

O presente trabalho avaliou a percepção e conhecimentos dos profissionais de saúde, lotados em uma unidade de ensino e assistência à saúde, acerca das funções de preceptoria e das políticas institucionais relacionadas à atuação de preceptores.

\section{Método}

A pesquisa foi aprovada pelo Comitê de Ética em Pesquisa da Universidade do Estado do Pará (CEP-Uepa), número de aprovação 441.400 de 31/10/13, e autorizada pela Universidade do Estado do Pará (Uepa). A abordagem metodológica foi transversal e qualitativa. Os dados foram coletados por meio de reuniões em grupos focais entre profissionais de nível superior, lotados na Unidade de Ensino e Assistência em Fisioterapia e Terapia Ocupacional (Ueafto).

A amostra foi constituída de 15 profissionais, sendo oito fisioterapeutas e sete terapeutas ocupacionais, que estavam em efetivo exercício de atividades no período da pesquisa e desenvolviam funções de preceptoria.

A Ueafto é um centro de reabilitação que atende usuários do SUS no estado do Pará, além de servir como local de prática de cursos de graduação e pósgraduação de instituições públicas com as quais mantém convênios.

Os participantes foram divididos por turno de trabalho e inseridos de forma randomizada, em quatro grupos focais, em dias previamente combinados com os voluntários da pesquisa e em seu local de trabalho. Dessa forma, os grupos foram constituídos por, no mínimo, três e no máximo cinco participantes e moderados pelo pesquisador. Os profissionais ficaram assim distribuídos: Grupo 1 com cinco profissionais do turno da manhã; Grupo 2 com três profissionais do turno da tarde; Grupo 3 com quatro profissionais do turno da manhã; e Grupo 4 com três 
profissionais do turno da tarde. Para garantir o sigilo dos dados dos participantes da pesquisa, cada um foi identificado com um número, relacionando-se a fala de cada participante com o respectivo número.

Os objetivos da pesquisa foram então propostos, e, em seguida, realizada a leitura conjunta de um texto relacionado à temática da pesquisa, a fim de estimular o debate entre os participantes. Após a leitura, os entrevistados relataram suas experiências e percepções acerca da atividade de preceptoria no local de trabalho. A discussão foi orientada por um roteiro elaborado pelo pesquisador, com o objetivo de aprofundar as questões levantadas pela pesquisa.

Os grupos focais foram organizados de acordo com a descrição da técnica de Minayo (2010), para quem um grupo focal constitui um tipo de entrevista ou conversa em grupos pequenos e homogêneos, visando a obter informações e aprofundar a interação entre os participantes, seja para gerar consenso, seja para explicitar divergências. O debate foi registrado em áudio, utilizando aplicativo de gravação de voz instalado em um aparelho celular (Apple®, modelo Iphone 4), e a fala dos profissionais foi transcrita após escuta atenta.

Os dados dos grupos focais foram analisados por meio da técnica de análise do discurso, cujos pressupostos básicos podem ser resumidos em dois: 1) o sentido de uma palavra, expressão ou proposição não existe em si mesmo, expressando posições ideológicas em jogo no processo sócio-histórico, no qual as formas de relação são produzidas; 2) toda formação discursiva dissimula, pela pretensão de transparência, a dependência das formações ideológicas (MINAYO, 2010).

A proposta de análise do discurso, que sai do campo da linguística e se coloca no interior das ciências sociais, é um bem inestimável para a pesquisa qualitativa, mesmo quando o pesquisador não a utiliza com todo o rigor técnico. Sua maior contribuição é gerar elementos para contextualização da fala dos participantes da pesquisa (MINAYO, 2010).

O procedimento de obtenção de dados desta pesquisa seguiu os preceitos da Declaração de Helsinque e do Código de Nuremberg, sendo respeitadas as Normas de Pesquisa envolvendo Seres Humanos (Rs. CNS 466/12) do Conselho Nacional de Saúde (CNS) e depois de todos os participantes que concordaram em participar da pesquisa terem assinado o Termo de Consentimento Livre e Esclarecido (TCLE). 


\section{Resultados e discussão}

A análise da fala dos pesquisados nos grupos focais permitiu perceber os principais empecilhos para a realização da atividade de preceptoria, que foram divididas em três categorias temáticas: capacitação de técnicos; relação entre preceptores e docentes/tutores; e forma como a gestão da unidade trata a atividade de preceptoria.

Esses temas são percebidos pelos profissionais como desorganização na condução da atividade de preceptoria, e o debate realizado nos diferentes grupos conduziu a uma percepção comum de que esses problemas devem ser solucionados, para que a atividade ocorra de maneira mais satisfatória. Pode-se observar isso nas seguintes falas dos entrevistados:

\footnotetext{
"Tem gente que é preceptor e não sabe o que é preceptoria (...) que eu me lembre, nós tivemos uma capacitação, se não 'tô' lembrada há 2, 3, 4 anos, entendeu? Há 'trocentos' anos, e nunca mais teve uma capacitação de preceptoria." (Participante 1)
}

"Eu nem sei nem quem é o coordenador de cada curso. Eu acho que deveria ter essa comunicação direta, para que fluísse melhor e para que o aluno da residência, ou até mesmo os da graduação conseguissem aproveitar mais." (Participante 2)

"Teve uma listagem agora. Eu sou uma das mais antigas preceptoras (...) e meu nome não constava lá. E isso na atual gestão. Então é uma ausência, eu também sinto. Se você for perguntar quem são os preceptores e onde eles estão, eu acho que não haverá essa informação." (Participante 1)

"Essa questão da organização é absurdamente perceptível. Por quê? A gente não tem nenhuma formalidade de ingresso desses residentes ou desses estagiários. Isso não existe de 'Esse aqui é o seu residente, ele vem tantas vezes na semana, aqui está sua ficha de avaliação...' Se eu sou preceptora, eu preciso estar fazendo uma avaliação dele. Como é que vai se dar esse processo de avaliação? Nós não temos orientação com relação a isso." (Participante 3)

Os dados encontrados na pesquisa realizada com os profissionais da Ueafto são similares aos coletados por outros pesquisadores em relação às barreiras ao efetivo exercício da preceptoria. Diversos fatores atuam como empecilhos para a realização do ensino-clínico, tais como: limitações de tempo, falta de apoio financeiro e institucional, falta de acesso a especialistas em educação, falta de acesso a espaços educativos adequados e recursos. Além disso, os preceptores normalmente gastam uma quantidade significativa de tempo extra ensinando, consequentemente, atendem menos pacientes e perdem renda (CAYLEY, 2011). 
Além do mais, os profissionais que atuam como preceptores no sistema público de saúde encontram muitas dificuldades em conseguir apoio institucional para se capacitar. Uma das formas de enfrentar esses problemas seria 0 desenvolvimento de projetos de integração ensino-assistência por parte das instituições, formando assim profissionais com perfil mais adequado às diretrizes político-sanitárias e trazendo benefício direto à população assistida pelo SUS (TRAJMAN et al., 2009).

\subsection{Capacitação profissional}

A capacitação dos profissionais da unidade analisada que atuam como preceptores é uma demanda bastante explicitada pelos participantes da pesquisa. Segundo eles, não há investimento em capacitação profissional para exercer a atividade de preceptoria. O profissional que atua como preceptor ou professor universitário necessita de capacitação específica, não podendo restringir a formação a um diploma de bacharel, um doutorado ou mesmo ao fato de atuar como bom profissional na área em questão (ROCHA; RIBEIRO, 2012).

"A gente também não tem orientação. Eu, pelo menos, tenho formação técnica. Não tenho tanta didática assim. Eu não tenho aquela didática mesmo do ensino." (Participante 14)

Os profissionais entrevistados não se sentem capacitados para as atividades que envolvem orientação de alunos de graduação ou de residência. Eles têm consciência sobre a própria formação universitária, que não foi dirigida para esse tipo de atuação profissional.

\footnotetext{
"Eu acho que a atividade do preceptor é uma atividade muito complexa. Eu acho que a maioria de nós não teve uma educação baseada em metodologias ativas, nossa formação foi na metodologia tradicional." (Participante 12)

"Quem não pesquisa é difícil dar uma orientação para um trabalho científico, você não tem essa vivência, então pra gente é difícil ser preceptor nesse sentido, e a universidade não nos dá esse retorno para ser preceptor." (Participante 15)
}

Uma das estratégias educacionais que podem ser utilizadas na capacitação de preceptores é a formação em metodologias ativas, pois por meio dessas metodologias, pode-se problematizar a realidade vivenciada pelo preceptor, possibilitando assim maior integração ensino-assistência. As metodologias ativas de aprendizagem podem ser utilizadas no espaço das residências multiprofissionais, cumprindo esse papel e agregando saberes provenientes de todos os núcleos Revista Educação Online, n. 19, jun-ago 2015, p.84-99 
profissionais presentes no serviço de saúde. Para isso, existe a necessidade de ampliar os investimentos em formação de recursos humanos para o SUS, além de garantir maior autonomia aos profissionais e ampliar os espaços de construção coletiva dentro dos serviços de saúde (SALVADOR et al., 2011).

A portaria do Ministério da Saúde no 1.996 de 2007 definiu algumas diretrizes, criando as Comissões Permanentes de Integração Ensino-Serviço, instâncias intersetoriais e interinstitucionais permanentes que participam da formulação, condução e desenvolvimento da Política de Educação Permanente em Saúde (BRASIL, 2009). Dentre essas atribuições, está a articulação entre instituições, para propor estratégias de formação de trabalhadores, à luz dos conceitos da educação permanente, bem como incentivar a adesão das instituições aos princípios, à condução e ao desenvolvimento da educação permanente em saúde.

Segundo as diretrizes do Ministério da Saúde, a formação profissional deve ser um processo contínuo, para consolidar as reformas do setor de saúde pública. Nesse sentido, a educação permanente em saúde é entendida como uma ação contínua, centrada no processo de trabalho, institucionalizada e multiprofissional, orientada para a melhoria da qualidade dos serviços de saúde (SUDAN; CORRÊA, 2008).

Como parte do processo de formação, uma importante instituição pública de ensino superior, a Universidade Federal do Rio de Janeiro, passou a oferecer, pioneiramente a partir de 2007, como iniciativa de qualificação dos preceptores do internato da graduação em medicina, um Curso de Formação de Preceptores:

Na UFRJ, o Curso de Formação Pedagógica para Preceptores do Internato Médico (Cfppim) constitui um exemplo desta empreitada. Com o intuito de colaborar com a formação dos futuros profissionais médicos, o Laboratório de Currículo e Ensino do Núcleo de Tecnologia Educacional para a Saúde (LCE/Nutes) deu início a um projeto: a realização do Cfppim. Desde 2007, forma turmas de preceptores com uma visão pedagógica inovadora. (ROCHA; RIBEIRO, 2012, p. 346)

O incentivo à qualificação de preceptores deve vir essencialmente da parte dos serviços de saúde e das instituições formadoras, nos quais são desenvolvidas atividades de assistência e ensino. As iniciativas de qualificação devem ser estimuladas, sendo, para tanto, necessário, que as instituições de ensino e os governos garantam os meios necessários para seu desenvolvimento. 


\subsection{Relação entre preceptores e docentes}

Além de problemas de capacitação, os profissionais da unidade de saúde analisada relatam dificuldades na relação com os docentes. $O$ trabalho coletivo entre os profissionais do ensino e da assistência é fundamental, para que haja maior integração nas ações. Entretanto, são constatados problemas:

"Da graduação, o professor abre a porta e diz: '-Oi! Posso deixar 10 alunos aí contigo?'. Ela (a mesma professora) aparecia para dizer: '-Olha, eu tô saindo, eu preciso sair. Eu deixo os alunos contigo. Eles fazem rodízio.' Então... Isso é muito chato, gente!" (Participante 2)

A relação não harmônica entre professores e preceptores em relação ao processo de ensino-aprendizagem gera distanciamento e fragmentação nas atividades didáticas, com prejuízo de um aspecto essencial para o melhor aproveitamento dos alunos: o feedback em relação ao aprendizado. Os preceptores, em sua maioria, não têm acesso a atividades didáticas programadas nem à formalização do ensino e, portanto, não podem dar esse retorno. Dobbie e Tysinger (2005) afirmam que há evidências no campo da psicologia de que o feedback, quando realizado de forma construtiva, melhora o desempenho dos alunos e a confiança em relação aos supervisores:

Estudantes de medicina e residentes necessitam do feedback de seus preceptores e o consideram um componente fundamental para a qualidade de sua educação clínica. O desenvolvimento de suas habilidades não depende apenas da prática, mas também da qualidade do feedback recebido, especialmente a respeito de possíveis dificuldades no processo de aprendizagem. (CÔTÉ; BORDAGE, 2012, p. 1.274)

\footnotetext{
"Existem duas professoras que se preocupam quando vão usar o ambulatório ou necessitam de algum paciente. Elas... Uma tenta falar comigo antecipadamente (...). E ficam acompanhando o atendimento. Existe, mas são uma ou duas pessoas." (Participante 2)

"Às vezes não tem nem a parceria com o docente. A gente tá sabendo que o aluno tá ali com aquele professor, mas a gente não tem nenhuma troca." (Participante 7)
}

Para evitar conflito e garantir a continuidade na linha de aprendizado, é fundamental haver algum espaço de interação entre docentes e os preceptores responsáveis pelos alunos. Os preceptores necessitam participar do planejamento das atividades propostas aos alunos. Na residência médica e internato que se utilizam de metodologias ativas, esses encontros são uma realidade: 
A frequência e a duração dos encontros favoreceram o processo de capacitação. $O$ desejo de conduzir de forma adequada e bem-sucedida a construção do processo local contribuiu de forma decisiva para o caráter formativo das reuniões. Esse talvez tenha sido um dos momentos mais férteis da capacitação coletiva dos docentes em Aprendizagem Baseada em Problemas (ABP) no curso de Medicina de Londrina. Embora não tenham sido constituídas com a finalidade de capacitar professores, mas, sim, de gerenciar os problemas surgidos durante a implementação dos módulos temáticos, as reuniões de tutores desempenharam também esse papel. (ALMEIDA; FERREIRA FILHO, 2008, p. 242)

\begin{abstract}
"A gente busca, a gente é acessível, mas às vezes por resistências institucionais a gente não sabe o que é passado na academia, por que é dividido, não é uma coisa integrada, não." (Participante 7)
\end{abstract}

Um dos fatores que dificultam a relação entre docentes e preceptores é o próprio cotidiano dos serviços de saúde, que muitas vezes prioriza apenas o atendimento em larga escala. Essa realidade funciona também como entrave à atuação multidisciplinar da equipe de saúde e ao acesso a um cuidado de forma integral. As divisões entre os diversos setores do saber acabam se refletindo na relação entre os profissionais (SALVADOR et al., 2011).

"Não fica clara a responsabilidade dos técnicos em relação a estes alunos [da graduação]. Eles vêm para utilizar o espaço da unidade." (Participante 6)

"Não há esse diálogo, eu não sei qual a resistência que a própria universidade tem, tanto da graduação quanto da pós-graduação em usar isso aqui realmente como uma instituição de ensino-serviço. A gente não tem uma integração real aqui." (Participante 12)

"No caso da Uepa, além dessa questão do treinamento que a gente não recebe, o nó mesmo é que a gente não tem uma reunião antes de o aluno começar, a gente não sabe quem é o tutor, e não recebe nada." (Participante 10)

"Aqui na Ueafto, eu não me sinto fazendo preceptoria, não acho que exista, até porque, quando a gente tá com o aluno (graduação), a professora vinha com os alunos, dava a aula dela e a gente não interferia muita coisa." (Participante 14)

A residência multiprofissional pode servir como estratégia para melhoria da relação entre docentes e preceptores, uma vez que uma das propostas é garantir a integralidade no cuidado em saúde ao usuário do SUS. A prática integrada entre as diversas profissões deve abordar toda a complexidade envolvida no processo do cuidado à saúde (SALVADOR et al., 2011).

Por outro lado, a residência acabou alterando a dinâmica do serviço, trazendo à tona necessidades antes não sentidas pelos profissionais que agora atuam como preceptores. Como não há planejamento que inclua essa residência na dinâmica da 
assistência, ela acaba atuando como fator de desestabilização da ordem vigente no serviço da saúde, impedindo o desenvolvimento de todo o potencial enquanto metodologia de formação de recursos humanos para o SUS (DALLEGRAVE; KRUSE, 2009).

Um dos papéis do preceptor é atuar como moderador na discussão de casos clínicos, tanto na graduação quanto em residência, mas essa discussão não deve ser feita distante dos pacientes, o que diminui as oportunidades do residente de desenvolver habilidades técnicas e observar o preceptor em ação. O preceptor deve acompanhar o residente executando atividades e the oferecer feedback adequado, detectando possíveis erros na conduta com pacientes e contribuindo para a melhoria na técnica e na relação com os usuários (BOTTI; REGO, 2011).

Os relatos dos participantes da pesquisa demonstraram problemas na relação entre preceptores e docentes. O educando se relaciona com um e outro em momentos diferentes e de maneira isolada, havendo na maioria dos casos poucas situações em que ambos - docente e preceptor - estejam presentes ao mesmo tempo. Além disso, o planejamento da disciplina cabe ao docente e esse, na maioria das vezes, não compartilha o plano de ensino com o profissional que atua na preceptoria.

Acreditamos ser necessária uma melhoria nessa relação, devendo haver uma parceria entre esses profissionais, que são importantes sujeitos do processo de educação em saúde, para que não haja lacunas no processo de ensinoaprendizagem dos estudantes de graduação em saúde e das residências.

\subsection{Gestão}

Os participantes da pesquisa questionaram a forma como a gestão da unidade estudada e da própria universidade vem organizando a atividade de preceptoria. A comunicação e o planejamento inadequados entre os coordenadores de programas de residência e os preceptores levam a falsas conclusões quanto aos objetivos de ensino (que nem sempre são os mesmos entre preceptores e programas). É fundamental que os coordenadores se assegurem de que a prática de ensino dos docentes atinja os objetivos dos projetos pedagógicos dos cursos de graduação e dos programas de residência. 
"A visão dos que 'estão lá em cima' não é realmente a visão da preceptoria, o valor real da preceptoria, e sim trazer o que as residências trazem pras instituições e pronto." (Participante 1)

Em uma pesquisa com farmacêuticos americanos que atuavam como preceptores, verificou-se que as necessidades sentidas por aqueles profissionais, na maioria das vezes. não eram conhecidas pelos diretores dos programas de preceptoria:

Os temas e conteúdos, no entanto, foram em geral determinados com base nas informações que os diretores do programa APPE (Advanced Pharmacy Practice Experiences) acreditavam necessários aos preceptores. Poucos programas foram desenvolvidos com base em temas solicitados pelos preceptores. (MITRA; CORELLI; AMBROSE, 2011, p. 3)

"Eles (gestão) avaliam pela produtividade. Eu posso passar a tarde fazendo artigos, orientando alunos, eu não vou ser vista como uma boa profissional, não no papel deles. Se você está interessado em fazer um mestrado, eles estão preocupados em como vai ficar o atendimento aqui. Não existe incentivo (à atividade de preceptoria). O incentivo aqui é produção." (Participante 14)

"Mas, também não há contrapartida da universidade. Por exemplo, a gente tem uma demanda para atender. Em nenhum momento se pensa: Será que o material, espaço físico é adequado para acrescentar tantos residentes ou tantos alunos? Não há contrapartida da universidade." (Participante 5)

A pesquisa de Lemos e Bazzo (2010) aponta que o conservadorismo docente e a desarticulação ensino-serviço são alguns dos fatores responsáveis pela crise na formação de recursos humanos para a saúde. Isso cria muitas dificuldades em relação à forma de gerir uma unidade, onde se desenvolve, além da assistência, o ensino em saúde.

A utilização de estratégias de descentralização e democratização da gestão e a experimentação de formas de organização do processo de trabalho em busca de modelos assistenciais coerentes com os princípios da reforma sanitária impõem uma reflexão crítica e a formulação de proposições relativas aos perfis profissionais, aos processos pedagógicos e, em última instância, à direcionalidade da política educacional em saúde. (LEMOS; BAZZO, 2010, p. 2.564)

Os participantes da pesquisa reconheceram que há resistência de alguns profissionais à atividade de preceptoria.

"Eu acho que tem um esforço (por parte da coordenação técnica), mas eu acho que tem uma resistência. A gente sabe de colegas nossos que são resistentes nessa interação." (Participante 7)

Também há a percepção de que o planejamento das atividades ocorre sem a participação dos profissionais. 
"As coisas aqui são impostas, são colocadas, as coisas não são dialogadas, então eu acho que quando não há essa construção coletiva é muito difícil as coisas andarem." (Participante 7)

As atividades de preceptoria devem incluir no planejamento reuniões regulares entre 0 corpo docente e os preceptores, para possibilitar 0 desenvolvimento de habilidades de ensino de ambos, entretanto, o relato dos profissionais entrevistados mostra realidade diferente.

"Acho que falta comunicação entre os gestores, porque os próprios coordenadores [coordenadores técnicos da Ueafto] não sabem o cronograma, porque não é repassado para eles" (Participante 11).

O relato dos respondentes revelou problemas no entrosamento entre a gestão do serviço e os profissionais, bem como na atuação da gestão. Um dos problemas mais proeminentes é a introdução de outra função, no caso, a função de preceptoria, aos profissionais que atuam em serviços de saúde, o que necessita mais atenção por parte dos gestores, para garantir condições adequadas no exercício da nova atribuição.

Uma formação dos profissionais de saúde que considere os valores, sentimentos, visão de mundo e diferentes visões do SUS implica em trabalhar conjuntamente a transformação das práticas profissionais e a organização do trabalho (PAGANI; ANDRADE, 2012). Tais transformações no espaço de trabalho, com inclusão de novas funções e a busca por transformar as práticas profissionais, devem ser acompanhadas pelos gestores responsáveis pela unidade de saúde. Além disso, para estimular a participação dos sujeitos envolvidos, a utilização de metodologias de gestão mais democráticas se faz necessária.

O processo de mudança de concepções é complexo e exige dos profissionais envolvidos interesse, paciência e perseverança, pois são as pessoas que devem ter as práticas ressignificadas. Portanto, um novo modelo de ensino pressupõe uma nova "cultura" pedagógica a ser incorporada pelas pessoas que constituem a instituição (TEÓFILO; DIAS, 2009).

A gestão do serviço das unidades de saúde que recebem alunos deve estreitar as relações com os gestores da universidade que demanda esses alunos e com preceptores e docentes. Isso possibilitará maior integração das ações de ensino e assistência, criando um clima amistoso e de parceria, necessário para o desenvolvimento das atividades a que se propõe a unidade. 
Os gestores devem proporcionar as condições para que as residências multiprofissionais e os cursos de graduação que atuam na unidade não apenas utilizem a preceptoria como campo de práticas para os alunos, mas que mantenham relação mais próxima com os profissionais do serviço, pois esses têm papel ativo na formação dos alunos.

\section{Conclusão}

A pesquisa demonstrou que os participantes da pesquisa têm a percepção de uma atividade de preceptoria desorganizada, principalmente devido à ausência de capacitação para o seu exercício, assim como da pouca integração entre preceptores e docentes e entre as coordenações técnicas e de curso. Por terem uma formação técnica voltada essencialmente para a assistência às pessoas, os preceptores não têm a segurança de estar realizando a atividade de ensino de maneira adequada, e percebem que seus conhecimentos para o exercício dessa atividade não têm o devido embasamento científico.

$\mathrm{Na}$ fala dos participantes da pesquisa, ficou claro que, para melhorar sua atuação como preceptores, é fundamental que ocorra capacitação pedagógica, possibilitando assim maior integração entre ensino e assistência. Segundo eles, é importante reconhecer que ainda há necessidade de um trabalho conjunto de planejamento entre os coordenadores de curso e os coordenadores técnicos da unidade e entre os preceptores e docentes, no sentido de prover as condições necessárias para o exercício pleno e efetivo da atividade de preceptoria.

Outro aspecto importante a ser observado é que a atividade de preceptoria não está devidamente institucionalizada no local pesquisado. Talvez, essa seja uma realidade de outras unidades de saúde, havendo a necessidade de regulamentá-la, com vistas a garantir uma maior valorização dos profissionais que a exercem. Com isso, ficaria assegurado o devido reconhecimento, tanto no campo profissional quanto acadêmico, tornando-os alvo das políticas de apoio e capacitação. 


\section{Referências bibliográficas}

ALMEIDA, H.; FERREIRA FILHO O. F. Educação permanente de docentes: análise crítica de experiências não sistematizadas. Revista Brasileira de Educação Médica, v. 32, n.2, p. 240-247, 2008.

BOTTI, S.H.; REGO, S. O. Docente clínico: o complexo papel do preceptor na residência médica. Physis, v. 21, n. 1, p. 65-85, 2011.

O papel do preceptor na formação de médicos residentes: um estudo de residências em especialidades clínicas de um hospital de ensino. Rio de Janeiro, 2009. Tese (Doutorado em Ciências da Saúde) - Escola Nacional de Saúde Pública Sérgio Arouca. Rio de Janeiro, 2009.

.Preceptor, supervisor, tutor e mentor: quais são seus papéis? Revista Brasileira de Educação Médica, v. 32, n. 2, p. 363-373, 2008.

BRASIL. MINISTÉRIO DA EDUCAÇÃO E CULTURA. Perguntas e respostas sobre residência multiprofissional e em área profissional da saúde. Disponível em: <http://portal.mec.gov.br/index.php?option=com_content\&id=18168\&ltemid=813\#17> . Acesso em 01/06/2014.

BRASIL. MINISTÉRIO DA SAÚDE. SECRETARIA DE GESTÃO DO TRABALHO E DA EDUCAÇÃO NA SAÚDE. DEPARTAMENTO DE GESTÃO DA EDUCAÇÃO EM SAÚDE. Política Nacional de Educação Permanente em Saúde. Brasília: MS, 2009.

CAYLEY, W.E. Effective clinical education: strategies for teaching medical students and residents in the office. WMJ, v.110, n.4, p. 178- 181, 2011.

CÔTÉ, L.; BORDAGE, G. Contentand conceptual frameworks of preceptor feedback related to residents' educational needs. Academic Medicine, v.87, n.9, p. 1274-1281, 2012.

DALLEGRAVE, D.; KRUSE, M. H. L. No olho do furacão, na itha da fantasia: a invenção da residência multiprofissional em saúde. Interface: comunicação, saúde, educação, v.13, n.28, p. 213-237, 2009.

DIAS, A. R. N.; FREITAS, J. J. S. A percepção e conhecimentos dos profissionais de saúde de uma unidade de ensino-assistência em relação à atividade de preceptoria. Belém, 2014. Dissertação (Mestrado em Ensino em Saúde na Amazônia) Universidade do Estado do Pará. Belém, 2014.

DOBBIE, A.; TYSINGER, J. Evidence-based strategies that help office-based teachers give effective feedback. Family Medicine, v.37, n.9, p. 617-619, 2005.

GADOTTI, M. Qualidade na educação: uma nova abordagem. 3o Congresso Brasileiro de Educação Básica, 3, 06 a 08 de fevereiro de 2013, Florianópolis, Conferência de Abertura. Florianópolis: Secretaria Municipal de Educação, 2013. Disponível em: <http://www.pmf.sc.gov.br/arquivos/arquivos/pdf/14_02_2013_16.22.16.85d3681692 786726aa2c7daa4389040f.pdf>. Acesso em 18/042015.

GIL, C.R.R. et al. Interação ensino, serviços e comunidade: desafios e perspectivas de uma experiência de ensino-aprendizagem na atenção básica. Revista Brasileira de Educação Médica, v.32, n.2, p. 230-239, 2008. 
LEMOS, M.; BAZZO, L. M. F. Formação do fonoaudiólogo no município de Salvador e consolidação do SUS. Ciência \& Saúde Coletiva, v.15, n.5, p. 2.563-2.568, 2010.

MINAYO, M.C.S. O desafio do conhecimento: pesquisa qualitativa em saúde. $12^{\mathrm{a}} \mathrm{ed}$. São Paulo: Hucitec, 2010.

MITRA, A.; CORELLI, R.; AMBROSE, P. Development needs of volunteer pharmacy practice preceptors. American journal of pharmaceutical education, v.75, n.1, p. 1-7, 2011.

PAGANI, R.; ANDRADE, L. O. M. Preceptoria de território, novas práticas e saberes na estratégia de educação permanente em saúde da família: o estudo do caso de Sobral, CE. Saúde e Sociedade, v.21, supl.1, p. 94-106, 2012.

ROCHA, H. C. RIBEIRO, V. B. Curso de Formação Pedagógica para Preceptores do Internato Médico. Revista Brasileira de Educação Médica, v.36, n.3, p. 343-350, 2012.

SALVADOR, A. S.; MEDEIROS, C. S.; CAVALCANTI, P. B.; CARVALHO, R. N. Construindo a multiprofissionalidade: um olhar sobre a residência multiprofissional em saúde da família e comunidade. Revista Brasileira de Ciências da Saúde, v.15, n.3, p. 329-338, 2011.

SANTOS, E.G.; FERREIRA, R. R.; MANNARINO, V. L.; LEHER, E. M. T.; GOLDWASSER, R. S.; BRAVO NETO, G. P. Avaliação da preceptoria na residência médica em cirurgia geral, no centro cirúrgico, comparação entre um hospital universitário e um hospital não universitário. Revista do Colégio Brasileiro de Cirurgiões, v. 39, n. 6, p. 547-552, 2012.

SUDAN, L.C.P.; CORRÊA, A.K. Práticas educativas de trabalhadores de saúde: vivência de graduandos de enfermagem. Revista Brasileira de Enfermagem, v. 61, n. 5, p. 576-582, 2008.

TEÓFILO, T.J.S.; DIAS, M.S.A. Concepções de docentes e discentes acerca de metodologias de ensino-aprendizagem: análise do caso do curso de enfermagem da universidade estadual do vale do acaraú em Sobral- CE. Interface: comunicação, saúde, educação, v. 13, n. 30, p. 137-151, 2009.

TOASSI, R. F. C.; DAVOGLIO, R. S.; LEMOS, V. M. A. Integração ensino-serviçocomunidade: o estágio na atenção básica da graduação em odontologia. Educação em Revista, v. 28, n. 4, p. 223-242, 2012.

TRAJMAN, A.; ASSUNÇÃO, N.; VENTURI, M.; TOBIAS, D.; TOSCHI, W.; BRANT, V. A preceptoria na rede básica da Secretaria Municipal de Saúde do Rio de Janeiro: opinião dos profissionais de saúde. Revista Brasileira de Educação Médica, v.33, n.1, p. 24-32, 2009. 